\title{
Perbandingan Model Asuhan Keperawatan Profesional Tim dengan Primary Nursing dalam Peningkatan Kualitas Asuhan Keperawatan di Rumah Sakit Kota Medan
}

\author{
Hendry Kiswanto Mendrofa ${ }^{1, *}$, Muhammad Taufik Daniel Hasibuan ${ }^{2}$ \\ ${ }^{1}$ STIKes Murni Teguh, Jl. Jawa No. 2, Medan 20231, Indonesia \\ ${ }^{2}$ Program Studi S1 Keperawatan STIKes Murni Teguh, Jl. Jawa No. 2, Medan 20231, Indonesia \\ 'hendrykiswanto155@gmail.com*; ${ }^{2}$ aniel.jibril@gmail.com; \\ * corresponding author
}

ARTICLE INFO

Article history

26-08-2021

$15-09-2021$

$02-10-2021$

Keywords

Team Nursing

Primary Nursing

Quality of Nursing Care

\begin{abstract}
The development of science and technology that continues to progress, especially in the health sector requires changes in terms of service so that in providing more professional services in hospitals, nursing care must be of high quality. Nursing Law Number 38 of 2014 Article 3B states that nursing arrangements aim to improve the quality of nursing services, therefore the provision of quality nursing services is important in today's health services. The model of professional nursing care is divided into several models, namely primary, team and case nursing. Based on the results of a survey of research journals, the researchers concluded that there was no research that compared the professional nursing care team model with primary nursing in improving the quality of nursing care. The purpose of this study was to identify the use of the professional nursing care team model with the primary nursing model in improving the quality of nursing care. This type of research is a quantitative research type with a comparative design. The population in this study were all patients at the Inpatient Hospital where the study was conducted. The sampling technique used was purposive sampling technique. Data collection on the quality of nursing care used a quality scale patient assessment instrument - the acute care version (PAQSACV). This instrument was developed to assess the quality of nursing care. Data analysis in this study used an independent t-test. normality test using the Kolmorogov-Smirnov test with a significance value ( $p$ > $0.05)$. The results showed that there was a significant difference between the quality of nursing care in the team group and the quality of nursing care in the primary nursing group where the value of sig (2tailed) was 0.008 where $>0.05$, the results also showed that based on the results of the frequency distribution test the quality of nursing care was using the team model and the primary nursing model has a high majority value of nursing care quality, but there is a difference in the average value (mean) where the quality of nursing care in the nursing care model group in the team method group is 144.86 and the quality of nursing care in the primary nursing model group is 155.83 . These results indicate that the quality of nursing care with the primary nursing model has a higher quality of care value than the group nursing care model with the team method. Based on the results of this study, it is recommended that hospitals can apply a professional nursing practice model, especially the primary nursing model to further improve the quality of nursing care provided.
\end{abstract}

\section{Pendahuluan}

Perkembangan ilmu pengetahuan dan teknologi yang terus mengalami kemajuan khusunya di bidang kesehatan menuntut adanya perubahan dari segi pelayanan, sehingga dalam memberikan pelayanan yang lebih profesional di rumah sakit maka pemberian asuhan keperawatan haruslah berkualitas [1]. Undang-undang keperawatan nomor 38 Tahun 2014 pasal 3B menyebutkan bahwa pengaturan keperawatan bertujuan untuk meningkatkan mutu pelayanan keperawatan, oleh sebab itu pemberian pelayanan keperawatan yang berkualitas menjadi penting dalam layanan kesehatan saat ini [2], Model asuhan keperawatan profesional dibagi beberapa model yaitu primary nursing, tim dan kasus, model asuhan keperawatan profesional primary nursing merupakan model 
penugasan perawat dimana perawat memiliki tanggungjawap selama 24 jam dalam proses pemberian asuhan kepada pasien dimulai dari pasien masuk sampai dengan pasien keluar [3], sedangkan metode tim adalah suatu keadaan dimana proses keperawatan dilakukan oleh sekelompok perawat terhadap sekelompok pasien di ruang perawatan yang terdiri atas kepala ruangan, ketua tim dan anggota tim [4].

Penelitian Mendrofa \& Sagala menyatakan bahwa ada perbedaan yang signifikan penerapan model asuhan keperawatan profesional (MAKP) primary nursing terhadap peningkatan kualitas asuhan keperawatan [5], hasil penelitian Adelia juga menunjukkan bahwa ada peningkatan kepuasan perawat dan pasien setelah dilaksanakan penerapan model asuhan keperawat profesional primary nursing [6]. Model asuhan keperawatan keperawatan profesional merupakan faktor yang berpengaruh terhadap kepuasan pasien, model tim berbanding lurus dengan peningkatan kualitas layanan dan kepuasan pasien [7], hasil penelitian Astuti \& Norhalimah juga menunjukkan ada hubungan yang signifikan antara penerapan metode tim keperawatan terhadap kualitas dokumentasi asuhan keperawatan [8].

Berdasarkan hasil survei dibeberapa rumah sakit di Kota Medan tentang model asuhan keperawatan profesional dari hasil tersebut peneliti mendapatkan mayoritas unit keperawatan sudah melaksanakan model tim dan ada beberapa Rumah Sakit sudah menggunakan model primary nursing, berdasarkan hasil survei jurnal penelitian, peneliti menyimpulkan bahwa belum ada penelitian yang membandingkan model asuhan keperawatan profesional tim dengan primary nursing.

\section{Metode}

Penelitian ini merupakan jenis penelitian kuantitatif dengan dengan desain komperatif yaitu untuk membandingkan model asuhan keperawatan profesional tim dengan model primary nursing dalam peningkatan kualitas asuhan keperawatan dirumah sakit, Penelitian ini dilaksanakan di Rumah Sakit di kota Medan yang menggunakan model asuhan keperawatan profesional primary nursing dan model asuhan keperawatan profesional tim. Populasi dalam penelitian ini yaitu seluruh pasien di ruang rawat Inap Rumah Sakit yang menjadi tempat penelitian. Teknik pengambilan sampel dengan menggunakan teknik Purposive sampling yaitu peneliti dengan sengaja memutuskan untuk memilih sampel yang dinilai menjadi khas dari populasi atau memiliki pengetahuan tentang masalah yang akan diteliti [9].

Pengumpulan data kualitas asuhan keperawatan menggunakan instrumen patient's assessment of quality scale-acute care version (PAQS-ACV), instrument ini dikembangkan untuk menilai kualitas asuhan keperawatan, instrumen patient's assessment of quality scale - acute care version (PAQS-ACV) terdiri dari 44 pernyataan dengan lima domain kualitas yang meliputi caring, responsiveness, individualization, nurse characteristics dan environment, dihitung menggunakan 4 poin skala likert (sangat tidak setuju, tidak setuju, setuju dan sangat setuju [10]. Berdasarkan hasil uji content validity index (CVI) instrumen patient's assessment of quality scale-acute care version (paqs-acv) diperoleh bahwa hasil CVI adalah 0.98. Uji reliabilitas ini menggunakan uji statistik cronbach alpha. hasil uji reliabilitas kuesioner Patient's assessment of quality scale - acute care version (PAQS-ACV) didapatkan nilai cronbach alpha yaitu 0,66 [1]. Data yang telah terkumpul melalui kuesioner dianalisis baik bivariate untuk mengetahui perbandingan model primary nusing dan model tim terhadap kualitas asuhan keperawatan menggunakan uji independent $t$-test, sebelum melakukan uji, peneliti melakukan uji normalitas dengan menggunakan uji kolmorogov-smirnov test dengan nilai kemaknaan $(\mathrm{p}>0,05)$.

\section{Hasil dan Diskusi}

Berikut ini akan diuraikan data hasil penelitian perbandingan model asuhan keperawatan profesional tim dengan primary nursing dalam peningkatan kualitas asuhan keperawatan di Rumah Sakit Kota Medan. Pelaksanaan pengumpulan data dilaksanakan kepada 70 responden dan penyajian hasil penelitian meliputi distribusi frekuensi data kualitas asuhan keperawatan dan hasil analisa perbedaan antara kelompok yang dibandingkan dalam penelitian ini. 
1) Analisa Univariat

Distribusi Frekuensi Kualitas Asuhan Keperawatan di Ruang Rawat inap pada Kelompok Model Asuhan Keprawatan Metode Tim

Berdasarkan hasil penelitian terhadap 35 responden akan disajikan distribusi kualitas asuhan keperawatan di ruang rawat inap pada kelompok model asuhan keperawatan metode tim, untuk masing-masing kategori dapat dilihat pada tabel berikut :

Tabel. 1. Distribusi Frekuensi Kualitas Asuhan Keperawatan di Ruang Rawat Inap pada Kelompok Model Asuhan Keperawatan Metode Tim $(\mathrm{n}=35)$

\begin{tabular}{ccccc}
\hline No. & & Kualitas Asuhan & Frekuensi $(\boldsymbol{f})$ & Persentase (\%) \\
\hline 1. & Rendah & & - & - \\
2. & Sedang & 10 & 28.6 \\
3. & Tinggi & & 25 & 71.4 \\
\hline & & Jumlah & $\mathbf{3 5}$ & $\mathbf{1 0 0 , 0}$ \\
\hline
\end{tabular}

Hasil penelitian terhadap 35 responden pada pasien di ruang rawat inap menunjukkan bahwa kualitas asuhan keperawatan di ruang rawat inap pada kelompok model asuhan keprawatan metode tim yaitu mayoritas berada pada kategori tinggi yaitu sebesar $71.4 \%$ dan minoritas berada pada kategori sedang yaitu sebesar $28.6 \%$.

\section{Distribusi Frekuensi Kualitas Asuhan Keperawatan di Ruang Rawat Inap Pada Kelompok Model Asuhan Keperawatan Metode Primary Nursing}

Berikut akan disajikan distribusi frekuensi kualitas asuhan keperawatan pada kelompok model asuhan keperawatan metode primary nursing, untuk masing-masing kategori dapat dilihat pada tabel berikut :

Tabel.2. Distribusi Frekuensi Kualitas Asuhan Keperawatan di Ruang Rawat inap Pada Kelompok Model Asuhan Keperawatan Metode Primary Nursing $(\mathrm{n}=35)$

\begin{tabular}{clcc}
\hline No. & Kualitas Asuhan & Frekuensi $(f)$ & Persentase (\%) \\
\hline 1. & Rendah & - & - \\
2. & Sedang & 2 & 5.7 \\
3. & Tinggi & 33 & 94.3 \\
\hline & Jumlah & $\mathbf{3 5}$ & $\mathbf{1 0 0 , 0}$ \\
\hline
\end{tabular}

Hasil penelitian pada tabel diatas menunjukkan bahwa kualitas asuhan keperawatan di ruang rawat inap pada kelompok model asuhan keprawatan metode primary nursing mayoritas berada pada kategori tinggi yaitu sebesar $94.3 \%$.

\section{2) Analisis Bivariat}

\section{a. Uji Distribusi Normal}

Uji normalitas digunakan untuk menguji apakah data subjek penelitian mengikuti suatu distribusi normal statistik. Uji distribusi normal sebagai syarat untuk dapat melaksanakan uji parametrik yaitu uji Independend T-Test, Setelah dilakukan uji normalitas dengan menggunakan uji Shapiro-Wilk ditemukan data berdistribusi normal dimana memiliki nilai $p>0.05$. hasil uji Shapiro-Wilk dapat dilihat pada tabel berikut ini :

Tabel.3. Uji Normalitas Data Kualitas Asuhan Keperawatan Kelompok Metode Tim dan Metode Primary Nursing

\begin{tabular}{lc}
\hline \multicolumn{1}{c}{ Kategori } & Signifikansi $(p)$ \\
\hline $\begin{array}{l}\text { Data kualitas asuhan keperawatan di ruang rawat inap } \\
\text { pada kelompok model asuhan keperawatan metode tim }\end{array}$ & .095 \\
$\begin{array}{l}\text { Data kualitas asuhan keperawatan di ruang rawat inap } \\
\text { pada kelompok model asuhan keperawatan metode } \\
\text { primary nursing }\end{array}$ & .184 \\
\hline
\end{tabular}


Berdasarkan tabel di atas menunjukkan bahwa nilai signifikansi $(p)$ untuk kualitas pada kelompok model asuhan keperawatan metode tim adalah .095 dan kualitas asuhan keperawatan pada kelompok model asuhan keperawatan metode primary nursing adalah .184, dimana nilai $p$ untuk kedua variabel > 0,05, maka disimpulkan data berdistribusi normal.

b. Perbandingan Model Asuhan Keperawatan Profesional Tim Dengan Primary Nursing dalam Peningkatan Kualitas Asuhan Keperawatan

Hasil Penelitian ini berikut ini untuk mengetahui perbandingan model asuhan keperawatan profesional tim dengan primary nursing dalam peningkatan kualitas asuhan keperawatan di Rumah Sakit Kota Medan.

Tabel.4. Uji Beda Mean Dengan Menggunakan Uji Independend T-Test Nilai Kualitas Asuhan Keperawatan Kelompok Metode Tim dan Metode Primary Nursing

\begin{tabular}{|c|c|c|c|c|c|}
\hline & $\mathbf{N}$ & Mean & $\begin{array}{c}\text { Mean } \\
\text { Difference }\end{array}$ & $\begin{array}{c}\text { Levene's Test } \\
\text { for Equality of } \\
\text { Variances }\end{array}$ & Sig. \\
\hline $\begin{array}{l}\text { Kualiatas Asuhan Keperawatan } \\
\text { Kelompok Model Asuhan } \\
\text { Keperawatan Metode Tim }\end{array}$ & 35 & 144.86 & -10.971 & \multirow{2}{*}{.102} & \multirow{2}{*}{.008} \\
\hline $\begin{array}{l}\text { Kualitas Asuhan Keperawatan Pad } \\
\text { Kelompok Model Asuhan } \\
\text { Keperawatan Metode Primary } \\
\text { Nursing }\end{array}$ & 35 & 155.83 & -10.971 & & \\
\hline
\end{tabular}

Berdasarkan tabel diatas hasil menunjukkan bahwa nilai rata - rata (mean) kualitas asuhan keperawatan pada kelompok model asuhan keperawatan metode tim adalah 144.86 dan kualiatas asuhan keperawatan pada kelompok model primary nursing adalah 155.83 berdasarkan hasil tersebut dapat menunjukkan bahwa secara statistik deskriptif dapat disimpulkan bahwa ada perbedaan yang berarti antara kualitas asuhan keperawatan pada kelompok tim dengan kualitas asuhan keperawatan pada kelompok primary nursing, hasil dari levene's test for equality of variances adalah .102 dimana $>0.05$ maka varian dari kedua kelompok tersebut diatas adalah homogen dan diketahuai nilai mean di Difference yaitu 10.971 artinya selisih antara nilai rata rata pada kelompok diatas adalah 10.971.

Berdasarkan hasil Uji Independend T-Test di ketahui nilaI sig (2-tailed) sebesar .008 dimana > 0.05 maka dapat disimpulkan bahwa ada perbedaan yang signifikan antara kualitas asuhan keperawatan pada kelompok tim dengan kualitas asuhan keperawatan pada kelompok primary nursing.

\section{Pembahasan}

Perbandingan Model Asuhan Keperawatan Profesional Tim Dengan Primary Nursing Dalam Peningkatan Kualitas Asuhan Keperawatan

Primary nursing adalah model metode penugasan perawat pada unit pelayanan keperawatan dimana perawa tmemiliki tanggungjawap selama 24 jam dalam proses pemberian asuhan kepada pasien terhitung dari pasien masuk sampai dengan pasien keluar, metode ini meningkatkan kemandirian perawat dalam proses pemberian asuhan dari pengkajian sampai dengan evaluasi [3]. Model metode penugasan perawat primary nursing yaitu menggunakan seorang perawat primer yang bertanggung jawab terhadap 5-6 pasien dan jika perawat primer tidak bertugas maka akan dilimpakan kepada perawat pelaksana dalam proses pemberian asuhan yang sudah dibuat oleh perawat primer [4]. Penelitian Mendrofa \& Sagala tentang pengaruh pelatihan dan penerapan model metode asuhan keperawatan profesional (MAKP) primary nursing terhadap kualitas asuhan keperawatan di Rumah Sakit Kota Medan, hasil penelitian menyatakan bahwa ada perbedaan yang signifikan antara kualitas asuhan keperawatan sesudah intevensi pada kelompok intervensi dengan kualitas asuhan keperawatan sesudah intervensi pada kelompok kontrol, hasil uji independend T-Test menunjukkan nilai sig (2-tailed) sebesar 0.00 dimana $<0.05$, sehingga dapat disimpulkan bahwa ada pengaruh penerapan model metode asuhan keperawatan profesional (MAKP) primary nursing terhadap peningkatan kualitas asuhan keperawatan [5].Hasil penetian 
Adelia tentang pengembangan model penugasan primary nursing di Ruang Rawat Inap Rumah Sakit Universitas Sumatera Utara juga menunjukkan bahwa ada peningkatan kepuasan perawat dan pasien setelah dilaksanakan penerapan model primary nursing [6]. Molin dkk juga menyatakan bahwa model primary nursing juga dapat meningkatkan kepuasan pasien dan kualitas asuhan yang diberikan [11]. Metode tim adalah suatu keadaan dimana proses keperawatan dilakukan oleh sekelompok perawat terhadap sekelompok pasien di ruang perawatan yang terdiri atas kepala ruangan, ketua tim dan anggota tim [4].

Hasil penelitian pengaruh penerapan metode tim terhadap kepuasan kerja perawat di unit stroke Rumah Sakit Panti Waluya Sawahan Malang menyimpulkan bahwa model asuhan keperawatan profesional tim dapat meningkatkan kepuasan para perawat dan diharapkan model tim dapat di terapkan dirumah sakit sehingga dapat memberikan pelayanan yang profesional dan komprehensif dengan mengutamakan kepuasan dan keselematan pasien [12].Penelitian ini juga sama hasilnya dengan penelitian yang dilakukan oleh Andriani dkk hasil penelitian menyimpulkan bahwa ada peningkatan kepuasan kerja terhadap penerapan model tim dengan kepuasan kerja 64,3\% penelitian ini dilaksanakan di di Rumah Sakit Dr. Saiful Anwar Malang [13]. Hasil penelitian juga menyatakan bahwa terdapatnya pengaruh sistem pemberian pelayanan keperawatan profesional model tim terhadap kepuasan pasien dan kepuasan perawat dengan nilai $p$-value adalah 0,00 hasil ini menyatakan pengaruhnya sangat signifikan, penelitian ini dilaksanakan di Intalasi Rawat Inap RSUD 45 Kuningan [14]. Hasil penelitian hubungan penerapan model tim dengan kinerja perawat pelaksana di Irna C RSUP Prof. DR. R. D. Kandou Manado, hasil penelitian menyatakan bahwa model asuhan keperawatan profesional tim memiliki hubungan terhadap kinerja perawat dimana jika model tim diterapkan maka ada peningkatan kinerja optimal para perawat sebesar $60.5 \%$ [15]. Penelitian Lobo dkk juga menyatakan bahwa Berdasarkan hasil uji statistik korelasi Spearman Rho menunjukan ada hubungan yang sangat kuat antara model asuhan keperawatan profesional tim dengan kinerja perawat di ruang Kelimutu, Komodo dan Anggrek RSUD Prof. Dr. W. Z. Johannes Kupang [16]. Kualitas keperawatan (quality nursing care) sebagai suatu proses yang berusaha untuk mencapai tingkat keunggulan tertinggi dalam memberikan perawatan, tanpa menyebabkan kerusakan, memenuhi kebutuhan, membantu untuk mencapai tujuan, pemeliharaan kesehatan dan pemulihan dari penyakit [17].

Kualitas keperawatan terfokus terhadap dua dimensi yaitu 1) apakah individu mendapatkan perawatan yang mereka butuh kan dan 2) apakah perawatan yang mereka terima telah efektif [18], terdapat enam elemen inti asuhan keperawatan yang berkualitas yaitu 1) pendekatan holistik dengan kebutuhan fisik, mental dan emosional, berpusat pada pasien dan perawatan yang terus menerusterus menerus, 2) efisiensi dan efektivitas yang dikombinasikan dengan rasa kemanusiaan dan rasa iba, 3) profesional, praktik berbasis bukti yang berkualitastinggi, 4) aman, efektif dan intervensi keperawatan yang tepat, 5) pemberdayaan pasien, dukungan dan advokasi, dan 6) pelayanan yang tulus melalui kerja sama tim yang efektif dengan profesi lain [16].

Banyak pakar telah menyatakan bahwa kualitas memiliki pengertiaan kompleks dan multi dimensi, dalam penelitian ini kualitas asuhan keperawatan dinilai dari perspektif pasien terhadap asuhan yang telah diterima, instrumen patient's assessment of quality scale - acute care version (PAQS-ACV) digunakan untuk menilai kualitas asuhan keperawatan [10].Lynn dkk menyimpulkan bahwa ada lima domain dari asuhan keperawatan yang berkualitas berdasarkan yaitu 1) caring, perhatian dan rasa peduli terhadap pasien, 2) individualization, seperti mengutamakan pasien, meyakinkan dan mendukung pasien dengan masalah yang dihadapi, memperlakukan pasien layaknya sebagai manusia, 3) responsiveness, ketanggapan perawat terhadap pasien, kesiapan perawat terhadap kebutuhan pasien, 4) nurse characteristics, seperti karakter dari setiap perawat ketika mereka memberikan pelayanan kepada pasien, perilaku dan sikap mereka ketika dekat dengan pasien, dan 5) environment, rasa nyaman terhadap lingkungan, memberikan lingkungan yang tenang pada pasien [10].

Model asuhan keperawatan profesional tim dan primary nursing adalah merupakan model praktek keperawatan profesional, hasil penelitian yang dilakukan oleh Asriani \& Mattalatta menyimpulkan bawa ada pengaruh model praktek keperawatan profesional (MPKP) di ruang rawat inap Rumah Sakit terhadap kualitas pelaksanaan standar asuhan keperawatan sebelum dan sesudah terhadap penerapan Model [19], begitu juga dengan hasil penelitian yang dilakukan oleh Sitorus tentang pengaruh implementasi model praktik keperawatan profesional terhadap mutu asuhan 
keperawatan menyimpulkan bahwa model praktek keperawatan profesional meningkatkan kualitas asuhan keperawatan [20].

\section{Kesimpulan}

Berdasarkan hasil penelitian perbandingan model asuhan keperawatan profesional tim dengan primary nursing dalam peningkatan kualitas asuhan keperawatan maka dapat diambil kesimpulan sebagai berikut:

1. Ada perbedaan yang signifikan antara kualitas asuhan keperawatan pada kelompok tim dengan kualitas asuhan keperawatan pada kelompok primary nursing berdasarkan hasil Uji Independend T-Test di ketahui nilaI sig (2-tailed) sebesar .008 dimana > 0.05

2. Berdasarkan hasil penelitian menunjukkan bahwa nilai rata - rata (mean) kualitas asuhan keperawatan pada kelompok model asuhan keperawatan metode tim adalah 144.86 dan kualiatas asuhan keperawatan pada kelompok model primary nursing adalah 155.83 menunjukkan bahwa secara statistik disimpulkan bahwa ada perbedaan yang berarti antara kualitas asuhan keperawatan pada kelompok tim dengan kualitas asuhan keperawatan pada kelompok primary nursing, dimana kelompok primary nursing memiliki nilai kualitas asuhan yang lebih tinggi dibandingkan dengan kelompok model asuhan keperawatan metode tim.

\section{Referensi}

[1] Mendrofa, H.K. Hubungan budaya kerja perawat dengan kualitas asuhan keperawatan berdasarkan perspektif pasien di ruang rawat inap rumah sakit umum daerah dr. Pirngadi Medan. Tesis : Fakultas Keperawatan Universitas Sumatera Utara. 2016.

[2] Undang-Undang Republik Indonesia No. 38 Tahun 2014. Tentang Keperawatan. 2014.

[3] Nursalam. Manajemen Keperawatan: Aplikasi dalam praktik keperawatan profesional. Edisi 4.Jakarta: Salemba Medika. 2014.

[4] Marquiz, B. L., \& Huston, C. J. Kepemimpinan dan manajemen keperawatan, Teori dan aplikasi. Jakarta. Edisi 4. EGC. 2010.

[5] Mendrofa, H. K., \& Sagala, L. Pengaruh pelatihan dan penerapan model metode asuhan keperawatan profesional (MAKP) primary nursing terhadap kualitas asuhan keperawatandi rumah sakit kota medan. Indonesia Trust Health Jounal. Vol 2. No. 2, 237-245. 2019.

[6] Adelia, G. Pengembangan Model Penugasan Primary Nursing di Ruang Rawat Inap Rumah Sakit Universitas Sumatera Utara. Tesis : Fakultas Keperawatan Universitas Sumatera Utara. 2019.

[7] Hidayah, N. Manajemen Model Asuhan Keperawatan Profesional (MAKP) Tim dalam Peningkatan Kepuasan Pasien di Rumah Sakit. Jurnal Kesehatan.Vol. VII. No. 2. 2014.

[8] Astuti, N., \& Norhalimah. Hubungan Penerapan Metode Tim Keperawatan Terhadap Kualitas Dokumentasi Asuhan Keperawatan Di Ruang Asoka RSUD. Ulin Banjarmasin. Borneo Nursing Journal. Vol.1.No.1. 2019.

[9] Polit, D. F., \& Beck, C. T. Nursing research: Generating and assessing evidence of nursing practice. $9^{\text {th }}$ edition. Philadelphia: Lippincott Williams \& Wilkins. 2012.

[10] Lynn, M.R., McMillen, B. J., \& Sidani, S. Understanding and measuring patients' assessment of the quality of nursing care. Nursing Research, 56 (3), 159-166. doi: 10.1097/01.nnr.0000270025.52242.70. 2008.

[11] Molin, D. A., Gatta, C., Gilot, B.C., Ferrua, R., Cena, T., Manthey, M., \& Croso, A. The impact of primary nursing care pattern : result from a before-after study. Journal of Clinical Nursing, 2, 5-6. 2018.

[12] Widiastuti, M.M.S., Widodo, D., \& Widiani, E. Pengaruh Penerapan Metode Tim Terhadap Kepuasan Kerja Perawat Di Unit Stroke Rumah Sakit Panti Waluya Sawahan Malang. Nursing News Journal, Vol 1, No 2. 2016.

[13] Andriani, L, Armanu, \& Kuswantoro. Kepuasan Kerja Perawat Pada Aplikasi Metode Tim Primer Dalam Pelaksanaan Tindakan Asuhan Keperawatan (Studi Kuantitatif di Rumah Sakit dr. Saiful Anwar Malang. Jurnal Aplikasi Manajemen. Vol 10, No. 2. 2012.

[14] Rohim, A. \& Pranatha, A. Pengaruh sistem pemberian pelayanan keperawatan profesional 
metode tim terhadap kepuasan pasien dan kepuasan perawat di Instalasi Rawat Inap Rumah Sakit Umum Daerah 45 Kuningan. Jurnal Ilmu-Ilmu Kesehatan Bhakti Husada Kuningan ,Vol. 6 , No. 2. 2017.

[15] Mogopa, C .P., Pondaag, L., \& Hamel, R..S. Hubungan penerapan metode tim dengan kinerja perawat pelaksana di IRINA C RSUP Prof. DR. R. D. Kandou Manado E-Journal Keperawatan (E-Kp), Vol1 No. 2. 2012.

[16] Lobo, Y., Herwanti, E., \& Yudowaluyo, A. Hubungan penerapan metode asuhan keperawatan profesional (MAKP) dengan kinerja perawat di Ruang Kelimutu, Ruang Komodo, dan Ruang Anggrek Rsud Prof. Dr. W. Z. Johannes Kupang. CHMK Nursing Scientific Journal. Vol. 3, No. 2. 2019.

[17] Zhao, S. H., \& Akkadechanunt, T. Patients perceptions of quality nursing care in a chinese hospital. International Journal of Nursing and Midwifery, 3(9), 145-149. ISSN 2141-2499. 2011.

[18] Claessen, S. J. J., Francke, A. L., Sixma, H. J., Veer, A. J. E. de., \& Deliens, L. Measuring relatives' perspective on the quality of palliative care: the consumer quality index palliative. Care Journal of Pain and Symptom Management, 45(5), 875-884. 2013.

[19] Asriani, A., \& Mattalatta, M. Pengaruh Penerapan Model Praktek Keperawatan Profesional (Mpkp) Terhadap Standar Asuhan Keperawatan Dan Kepuasan Kerja Perawat Di Ruang Rawat Inap Rumah Sakit Bhayangkara Makassar. Jurnal Mirai Management, 2(1), 1-14. 2017.

[20] Sitorus, R. Dampak Implementasi Model Praktik Keperawatan Profesional Terhadap Mutu Asuhan Keperawatan di Rumah Sakit. Jurnal Keperawatan Indonesia, 7(2), 41-47. 2003. 